\title{
EDITORIAL
}

\section{Doing more of less: what registry data tell us about death in PICU}

\author{
Thomas Brick ${ }^{1 *}$ and Roger C. Parslow ${ }^{2}$
}

(c) 2019 Springer-Verlag GmbH Germany, part of Springer Nature

The development of paediatric critical care registries, a term we take to include national audits and research databases, has been instrumental in helping us understand the state of children's critical care and thereby provide a platform for future improvement. Comprehensive datasets enable monitoring of activity and outcomes for audit, safety and service planning. Registry databases play a crucial role in paediatric critical care research by providing information for observational studies and data to plan multicentre interventional clinical trials. There are a number of examples: the Paediatric Intensive Care Audit Network (PICANet) collects data for every admission to paediatric intensive care units (PICU) in the UK and Ireland, and the Australian and New Zealand Paediatric Intensive Care Registry (ANZPICR) collects data for children admitted to PICUs and adult intensive care units. Virtual Pediatric Systems (VPS) is a large database covering over 135 units and over 1 million cases in the USA, but does not collect data from all national PICUs.

Paediatric intensive care medicine has a number of features, which expose the methodological problems of studies involving either one or few centres. Admission numbers and mortality rates are low (see Table 1). Infants and children in PICU present with a heterogeneous range of primary illness and co-morbidities, and the age range is broad-over $40 \%$ of admissions are under 1 year of age and a small number $(2.4 \%)$ over 15 [1] -meaning that the pathophysiology of paediatric critical illness is hugely varied. Aggregation of data in registries helps us to overcome the problem of small numbers and describe patient characteristics, treatments and outcomes.

*Correspondence: thomas.brick@gosh.nhs.uk

1 Cardiac Intensive Care Unit, Great Ormond Street Hospital,

London WC1N 3JH, UK

Full author information is available at the end of the article
Use of registry databases to monitor safety and drive quality improvement is well described [2]: this includes transparent reporting of outcomes based on nationally or internationally agreed benchmarks in order to ensure safety and quality. Additionally, registries offer a wellestablished platform for observational studies, leading to a large body of research describing ICU processes, disease states and therapeutic interventions. Linking datasets-for example linking PICU databases to national hospital episodes datasets to provide detailed diagnostic information on children with life-limiting conditions [3]-enhances their explanatory power. Paediatric intensive care databases use mortality prediction models to enable participating units to benchmark their outcomes, and in turn, the data contributed by the participating units are used to construct and update these models in a symbiotic relationship [4]. Although registry studies are observational and hence cannot demonstrate causality, they are integral to the design and conduct of paediatric clinical trials. Databases can be interrogated in the planning stage, to provide epidemiological and outcome data for the diseases or treatments of interest. The data collection infrastructure can then be harnessed to provide high-quality data to the trial. The ChiP trial of tight glycaemic control in critically ill children [5], the CATCH trial of antibiotic impregnated central venous catheters [6] and the ongoing I-KID trial of infant kidney dialysis and filtration are good examples of this [7]. Recent interest has focussed on registry-based randomised trials [8] which, despite the potential challenges of consent, standardisation and quality of data, may represent a future avenue for high-quality, low-cost clinical trials in PICUs.

Moynihan and colleagues [9] have produced an excellent example of the powerful insights offered by a wellestablished and comprehensive paediatric intensive care registry. In this binational 11-year retrospective study of child death in Australia and New Zealand, children

\section{望 Springer}


admitted to intensive care were identified via ANZPICR. In addition, data from the national census of both countries were used to provide population-based mortality data over the study period. The authors report a decline in both crude and risk-adjusted ICU mortality $(0.1 \%$ per year) over the 11-year period. $12 \%$ of all child deaths in Australia and New Zealand occurred in ICU. Data on mode of death of children in ICU are presented, indicating that half the deaths occurred following withdrawal of life-sustaining therapy, the rate of death despite maximal support was $21 \%$ and fell by $0.9 \%$ per year, and the rate of diagnosis of brain death rose.

Moynihan and colleagues report longitudinal trends on mode of death from this binational dataset, which is unique in paediatric critical care medicine and comparable in scope to large adult data sets (see Table 1). Some encouragement can be found in the decrease in the proportions of deaths taking place despite maximal support; however, questions remain about the role intensive care should play at the end of life for many of these children and their families. Such debates are informed by registrybased research: three decades of data from a single centre in Australia demonstrated that children who would not have been offered intensive care at the beginning of the period are now surviving with moderate or severe disability [10]. A large longitudinal database study from all the PICUs in England showed that 58\% of PICU admissions and $73 \%$ of PICU deaths were for children with lifelimiting conditions [11]. In addition, children are taking longer to die on the PICU with a pattern of early death due to treatment failure being replaced by death following a prolonged PICU admission [12]. Moynihan and colleagues use their findings to call for an increase in the use of advance planning and palliative care involvement for critically ill children. They are right to do so, and this should form part of a wider discussion [13] about the role that intensive therapies should play in the lives of critically ill children, many of whom are likely to die in childhood.

To fully understand the impact of critical illness on children and families, there is a need to collect highquality longitudinal data from multiple data sources in a standardised format that will measure the range of outcomes and complexity of processes involved. Understanding the whole patient journey from illness onset to discharge is vital to allow informed, evidence-based planning of paediatric health services. Collecting these additional data will involve the need for funding, technical expertise and governance approvals at a national level. At an international level, harmonising definitions and then using these complex longitudinal data will provide insight into the effects of different organisational social and health structures on the delivery of paediatric critical care. Armed with this information, society can make an informed choice about how, where and what care for critically ill children is delivered in the future.

Table 1 Population differences and differing modes of death in paediatric and adult ICUs. (Adapted and updated from Kanthimathinathan and Scholefield [14])

\begin{tabular}{|c|c|c|c|c|}
\hline & \multicolumn{3}{|l|}{ PICU } & Adult ICU \\
\hline Intensive care units in England Wales and NI & \multicolumn{3}{|l|}{29} & 251 \\
\hline Admissions in 2017 & \multicolumn{3}{|l|}{16,979} & 175,700 \\
\hline Admissions per 100,000 population & \multicolumn{3}{|l|}{$143^{*}$} & $354^{* *}$ \\
\hline Mortality at discharge from ICU & \multicolumn{3}{|l|}{$3.7 \%$} & $13.8 \%$ \\
\hline \multirow{3}{*}{ Mode of death } & Moynihan [9] & Burns [15] & Sands [16] & ICNARC [17] \\
\hline & $\begin{array}{l}\text { Registry Aus + NZ } \\
2006-2017\end{array}$ & $\begin{array}{l}5 \text { US PICUs } \\
2010-2011\end{array}$ & $\begin{array}{l}\text { Single UK PICU } \\
1997-2007\end{array}$ & $\begin{array}{l}\text { National Audit } \\
\text { 2017-2018 }\end{array}$ \\
\hline & $n=2672$ & $n=192$ & $n=204$ & $n=23,441$ \\
\hline Declaration of brain death (\%) & 16.1 & 16 & 24.5 & 5.5 \\
\hline Maximal therapy (\%) & 21.1 & 14 & 10.9 & 30.3 \\
\hline Treatment withdrawn/withheld (\%) & 62.8 & 70 & 54.9 & 64.2 \\
\hline
\end{tabular}

ICNARC does not systematically report these data. We have assumed that deaths not following withholding/withholding of treatment, or following declaration of brain death, are deaths despite maximal therapy

Paediatrics Paediatric Intensive Care Audit Network Annual Report 2018 [1]

Adults Key statistics from the Case Mix Programme: 2017-2018, Intensive Care National Audit and Research Centre (ICNARC) [17]

Population Office for National Statistics [18]

${ }^{*}$ Children $<16$ years

${ }^{* *}$ Adults $>16$ years 


\section{Author details}

${ }^{1}$ Cardiac Intensive Care Unit, Great Ormond Street Hospital, London WC1N

3JH, UK. ${ }^{2}$ School of Medicine, University of Leeds, Leeds LS2 9JT, UK.

\section{Acknowledgements}

The authors would like to thank Professor David Harrison for advice on the ICNARC dataset.

\section{Compliance with ethical standards}

\section{Conflicts of interest}

Dr. Brick and Dr. Parslow have no conflicts of interest to disclose.

\section{Publisher's Note}

Springer Nature remains neutral with regard to jurisdictional claims in published maps and institutional affiliations.

Received: 11 June 2019 Accepted: 25 July 2019

Published online: 16 August 2019

\section{References}

1. Paediatric Intensive Care Audit Network Annual Report (2018) Universities of Leeds and Leicester. http://www.picanet.org.uk/

2. Wetzel R (2016) Pediatric intensive care databases for quality improvement. J Pediatr Intensive Care 05:081-088. https://doi. org/10.1055/s-0035-1568146

3. Fraser LK, Parslow R (2018) Children with life-limiting conditions in paediatric intensive care units: a national cohort, data linkage study. Arch Dis Child 103:540-547. https://doi.org/10.1136/archdischild-2017-312638

4. Straney L, Clements A, Parslow RC et al (2013) Paediatric index of mortality 3. Pediatric Crit Care Med 14:673-681. https://doi.org/10.1097/ PCC.0b013e31829760cf

5. Macrae D, Grieve R, Allen E et al (2014) A randomized trial of hyperglycemic control in pediatric intensive care. N Engl J Med 370:107-118. https:// doi.org/10.1056/NEJMoa1302564

6. Gilbert RE, Mok Q, Dwan Ket al (2016) Impregnated central venous catheters for prevention of bloodstream infection in children (the CATCH trial): a randomised controlled trial. Lancet 387:1732-1742. https://doi. org/10.1016/S0140-6736(16)00340-8
7. Walker J (2017) Infant kidney dialysis and filtration: the I-KID study. ISRCTN. https://doi.org/10.1186/isrctn13787486

8. Lauer MS, D'Agostino RB (2013) The randomized registry trial-the next disruptive technology in clinical research? N Engl J Med 369:1579-1581. https://doi.org/10.1056/NEJMp1310102

9. Moynihan KM, Alexander PMA, Schlapbach LJ et al. (2019) Epidemiology of childhood death in Australian and New Zealand intensive care units. Intensive Care Med 42:1039-1044, 2101. https://doi.org/10.1007/s0013 4-019-05675-1

10. Namachivayam P, Shann F, Shekerdemian L et al (2010) Three decades of pediatric intensive care: Who was admitted, what happened in intensive care, and what happened afterward. Pediatric Crit Care Med 11:549-555. https://doi.org/10.1097/PCC.0b013e3181ce7427

11. Fraser LK, Parslow R (2017) Children with life-limiting conditions in paediatric intensive care units: a national cohort, data linkage study. Arch Dis Child Archdischild. https://doi.org/10.1136/archdischild-2017-312638

12. Plunkett A, Parslow RC (2016) Is it taking longer to die in paediatric intensive care in England and Wales? Arch Dis Child 101:798-802. https://doi. org/10.1136/archdischild-2015-309592

13. Pearson GA (2018) Intensive care: because we can or because we should? Arch Dis Child Archdischild. https://doi.org/10.1136/archdischild-2017314731

14. Kanthimathinathan HK, Scholefield BR (2014) Dilemmas in undertaking research in paediatric intensive care. Arch Dis Child 99:1043-1049. https //doi.org/10.1136/archdischild-2013-304871f

15. Burns JP, Sellers DE, Meyer EC et al (2014) Epidemiology of death in the PICU at five US teaching hospitals*. Crit Care Med 42:2101-2108. https:// doi.org/10.1097/CCM.0000000000000498

16. Sands R, Manning JC, Vyas H, Rashid A (2009) Characteristics of deaths in paediatric intensive care: a 10-year study. Nurs Crit Care 14:235-240. https ://doi.org/10.1111/j.1478-5153.2009.00348.x

17. ICNARC (2018) Key statistics from the Case Mix Programme-adult, general critical care units. https://www.icnarc.org/DataServices/Attachment s/Download/70e9c741-5f0f-e911-80ef-1402ec3fcd79. Accessed 1 April 2017-31 March 2018

18. Office for National Statistics (2018) Population estimates for UK, England and Wales, Scotland and Northern Ireland: Mid-2017. https://www.ons. gov.uk/peoplepopulationandcommunity/populationandmigration/ populationestimates/datasets/populationestimatesforukenglandandw alesscotlandandnorthernireland. Accessed 11 June 2019 